\title{
The use of thermography to assess the teeth temperature during resection by grinding in piglets
}

by V. Redaelli*, F. Luzi ${ }^{\star}$, M. Farish ${ }^{\star \star \star}$ and L. Nanni Costa**

*Dept. of Animal Science, University of Milan, via Celoria, 10 - 20133 Milano, Italy, vereda@tin.it, fabio.luzi@unimi.it,

${ }^{\star \star}$ Dept. of Protection and Valorization of Agro-food, University of Bologna, via Fanin, 46 - 40127 Bologna, Italy, leonardo.nannicosta@unibo.it

***SAC, Animal Behaviour and Welfare, Sustainable Livestock Systems, Bush Estate, Penicuik, Edinburgh EH26 OPH, UK, Scotland, Marianne.Farish@sac.ac.uk

\begin{abstract}
Teeth resection of piglets within 24 hours of birth is a practice commonly applied to avoid damage to the sow's udder. The aim of the study was to understand if infrared thermography can be used to determine temperatures reached by teeth and mouth of piglets during resection by grinding. The procedure was performed using an electric grind stone on four piglets. Infrared thermographic video was taken at 30 frames per second. Grinding of teeth carried out with proper handling did not cause heating to the softer tissues of the mouth and the thermographic technique is pivotal in evaluate its effects.
\end{abstract}

\section{Introduction}

Teeth resection of piglets within 24 hours of birth is a practice commonly applied in commercial farms to avoid injuries to the face of littermates during establishment of teat orders and long term damage to the sow's udder [1]. Opinion about whether to resection and what is the best technique is not unanimous among researchers and the debate is very heated [2]. A preliminary study was implemented to ascertain whether thermographic techniques could be used to determine temperatures reached by the teeth and mouth of piglets during resection by grinding [3]. Clipping was not tested as the process does not inflict heat. As the area under investigation is small it is also important to test whether the thermographic techniques applied are able to provide data usable in this application.

The aim of the study was to understand if infrared thermography technique can be used to determine temperatures reached by teeth and mouth of piglets during resection by grinding.

\section{Materials and methods}

The procedure was performed by an experienced operator using an electric grind stone on four piglets 16 hours after birth. Infrared thermographic video was taken at 30 frames per second with Avio thermal imaging camera model TVS500 (Table 1) a distance of $40 \mathrm{~cm}$ from the mouth of each piglet throughout the procedure.

The resection of teeth by grinding was correctly performed. Thus, the temperature $(T)$ rise was confined to the teeth themselves and does not extend to any other part of the mouth.

The average baseline temperature of the mouths of pigs was $37^{\circ} \mathrm{C}$. The teeth grinding procedure took on average 120 seconds per piglet to accomplish. The average time grinders were applied to each tooth was 8 seconds.

\section{Results and discussion}

Immediately on application of the grinder the average tooth $\mathrm{T}$ reached was $50^{\circ} \mathrm{C}$ during the 2 seconds. The peak temperature of a tooth reached was $88^{\circ} \mathrm{C}$ for a sub-second interval. Teeth took 2 seconds on average to cool back to baseline temperature.

It is actually possible to record a thermographic video during the grinding of the teeth of piglets without interfering with the procedure and collect valuable useable data. However, it is imperative to use a camera with spatial resolution at least equal to that of the TVS500, to ensure the accuracy of the temperature values obtained on small objects such as teeth. Teeth frequently reach temperatures of $50-55^{\circ} \mathrm{C}$ during grinding, and came close to $90^{\circ} \mathrm{C}$ in some moments of the operation, although for only sub-second intervals. 


\section{Conclusion}

It would seem that, with proper handling, grinding of teeth does not cause heating to the softer tissues of the mouth and only effects the tooth for a very short period of time. Further behavioural and physiological examinations would need to be carried out in a larger study to assess the overall effect of grinding on the welfare of the piglet and to further investigate the debate on the most suitable procedure for tooth resection of piglets. Thermography is a very new and unique technique which supplies great detail and could be pivotal in understanding the true effects of such procedures on piglets.

\section{REFERENCES}

[1] Lewis E., Boyle L.A., Brophy P., O'Doherty J.V., Linch P.B., "The effect of two piglet teeth resection procedure on the welfare of sows in farrowing crates". Part 2. Applied Animal Behaviour Science, vol. 90, pp. 233-249, 2005.

[2] Gallois M., Le Cozler Y., Prunier A.,"Influence of tooth resection in piglets on welfare and performance". Preventive Veterinary Medicine, Vol. 69, pp. 13-23, 2005.

[3] Speakmen J.R. and Ward S., "Infrared thermography: Principle and applications". Zoology, vol. 101, pp 224232, 1998.

Table 1. Technical characteristics of thermocamera AVIO TVS500

\begin{tabular}{|c|c|}
\hline Measurement range & -40 to $500^{\circ} \mathrm{C}$ : Standard to $2000^{\circ} \mathrm{C}$ \\
\hline Temperature resolution & Better than $0.05^{\circ} \mathrm{C}$ with Averaging \\
\hline Accuracy & $\pm 2^{\circ} \mathrm{C}$ or $\pm 2 \%$ *1 \\
\hline Frame time & $1 / 60$ seconds \\
\hline Detector & Uncooled FPA, $320(\mathrm{H}) \times 240(\mathrm{~V})$ VOx microbolometer \\
\hline Wavelength & 8 to $14 \mu \mathrm{m}$ \\
\hline FOV & $19.4^{\circ}(\mathrm{H}) \times 14.6^{\circ}(\mathrm{V})$ (with standard $22 \mathrm{~mm}$ lens) \\
\hline Spatial resolution & $1.07 \mathrm{mrad}$ \\
\hline Measurement distance & $30 \mathrm{~cm}$ to $\infty$ \\
\hline Effective pixels & $320(H) \times 240(V)$ \\
\hline
\end{tabular}

Fig. 1. Thermographic images collected from the video recorded during teeth resection by grinding.

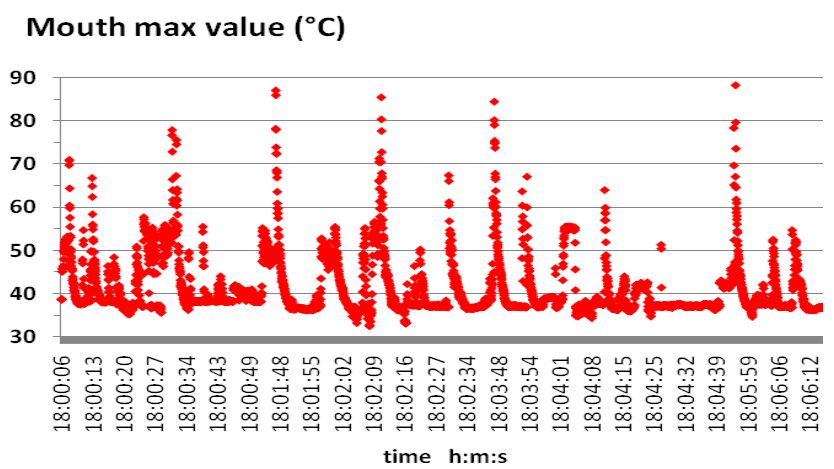

Fig. 2. Time variation of the max value of temperature reached in the mouth of the four piglets during teeth resection by grinding. 